\title{
Sample attrition analysis in a prospective cohort study of medical graduates in China
}

\author{
Mingyue Li ${ }^{1,2}$, Ziyue Wang ${ }^{2}$, Baisong Zhang ${ }^{1,2}$, Tiantian Wei ${ }^{1,2}$, Dan Hu² and Xiaoyun $\mathrm{Liu}^{1,2^{*}}$
}

\begin{abstract}
Background: A major challenge of prospective cohort studies is attrition in follow-up surveys. This study investigated attrition in a prospective cohort comprised of medical graduates in China. We described status of attrition, identified participants with higher possibility of attrition, and examined if attrition affect the estimation of the key outcome measures.

Methods: The cohort study recruited 3,620 new medical graduates from four medical universities in central and western China between 2015 and 2019. Online follow-up surveys were conducted on an annual basis. Follow-up status was defined as complete (meaning that the participant completed all the follow-up surveys) and incomplete, while incomplete follow-up was further divided into 'always-out','rejoin' and 'other'. Multivariable logistic and linear regressions were used to examine factors predicting attrition and the influence on the outcome measures of career development.
\end{abstract}

Results: 2364 (65.3\%) participants completed all follow-up surveys. For those with incomplete follow-up, 520 (14.4\%) were 'always-out', 276 (7.6\%) rejoined in the 2020 survey. Willingness to participate in residency training (OR=0.80, $95 \% \mathrm{Cl}[0.66-0.98])$ and willingness to provide sensitive information in the baseline survey predicted a lower rate of attrition (providing scores for university entrance exam $\mathrm{OR}=0.82,95 \% \mathrm{Cl}[0.69-0.97]]$; providing contact information $(\mathrm{OR}=0.46,95 \% \mathrm{Cl}[0.32-0.66])$; providing household income (OR=0.60, 95\%Cl[0.43 - 0.84]). Participants with compulsory rural service $(\mathrm{OR}=1.52,95 \% \mathrm{CI}[1.05-2.19])$ and those providing university entrance scores $(\mathrm{OR}=1.64,95 \% \mathrm{CI}[1.15$ 2.33)) were more likely to rejoin in the follow-up survey. These factors associated with follow-up status did not have significant impact on key outcome measures of career development.

Conclusions: Graduates who were unwilling to participate in residency training or not providing sensitive information should be targeted early in the cohort study to reduce attrition. More information about the study should be provided to those graduates early to facilitate their understanding of the meaning in participation. On the contrary, medical graduates with compulsory rural service and those who provided university entrance scores were more likely to rejoin in the cohort. The research team should invest more effort in contacting those graduates and returned them to the cohort.

Keywords: Attrition, Cohort study, Medical graduates

*Correspondence: xiaoyunliu@pku.edu.cn

${ }^{1}$ Department of Health Policy and Management, School of Public Health,

Peking University, Beijing, China

Full list of author information is available at the end of the article

\section{Background}

Longitudinal medical graduates' cohort studies are invaluable for investigating workforce participation, career development, and mobility of young health professionals, providing insights into the dynamics of the health labor market, and providing guidance for policy-making related to human resources for health $[1,2]$. However, 
one of the key challenges of prospective cohort studies is participant attrition. Attrition is often cumulative so that the non-responders can be a significant proportion of the original sample after a few follow-up surveys, reducing the sample size and thus decreasing the power of estimation [3]. The attrition might happen selectively, and reduce the representativeness of the sample over time and introduce bias [4].

Compared with surveys of general population in social and political sciences or patients in epidemiology, health workers tend to have a lower response rate $[5,6]$. For example, in the prospective cohort study of "Medicine in Australia: balancing employment and life (MABEL)" [7, 8], after three follow-up surveys, $34.6 \%$ of the GPs and $33.2 \%$ of the specialists were lost-to-follow-up due to attrition [3]. In addition, the response rates to surveys of health professionals are found to be declining over time, from over $80 \%$ in the $1950 \mathrm{~s}$ to less than $50 \%$ now [6].

To understand the facilitators of attrition of cohort study in general population, previous studies have found that men, unmarried, current smokers, low socioeconomic status, and poorer health can predict a higher possibility of lost-to-follow-up [9-11]. Young people are also less likely to continuously stay in the cohort compared to older people [11-13]. However, a limited body of research has examined attrition in prospective cohorts specific to young health professionals or young medical graduates, although younger age and health workers are both related to the higher possibility of attrition.

The Cohort Study of Medical Graduates with Compulsory Services in Rural Areas Study was launched in 2015 in four major medical universities from three provinces in China. It is a prospective cohort study comprised of young medical graduates who have just finished their undergraduate medical education. This study was initiated to examine the Compulsory Services Program (CSP) launched in 2010 by the Chinese government [14], which aimed to provide well-trained general practitioners (GP) for rural and remote areas. According to this policy, CSP students do not need to pay for tuition or accommodation during five-year undergraduate study and can receive monthly allowances. In exchange, they need to sign contracts with local health administrations and medical universities on matriculation and commit to going to the appointed township health centers or village clinics to practice for six years after graduation. Maintaining response rate is one of the key challenges in our follow-up surveys, with the concern that sample attrition might introduce considerable bias into the results and conclusions of the cohort study.

In this article, we analyzed the data from this prospective cohort study to investigate the following three questions: (1) what is the status of attrition in a prospective cohort comprised of young medical graduates? (2) in such a cohort, which type of participants are prone to attrition? (3) to what extent does the attrition affect the estimation for key outcome measure of the cohort study? The findings of this paper can provide useful reference for other cohort studies with health professionals to deal with attrition issues.

\section{Methods}

\section{Study design and data collection}

The Cohort Study of Medical Graduates with Compulsory Services in Rural Areas Study is a prospective cohort that investigates the medical study, residency training, employment, and career development of medical graduates, in order to contribute to the development of health workforce in rural and remote areas in China. The study was approved by the institutional review board (IRB) at Peking University Health Science Center (IRB0000105215027). All participants provided informed consent. In 2015, the first batch of medical graduates trained by CSP graduated after receiving five-year undergraduate study, so we established the first sub-cohort and collected baseline survey at four medical universities since then [15-17]. All CSP classes in the four universities were included in the cohort, and the participation rate was $100 \%$ at recruitment. CSP classes were matched with corresponding same-year NCSP classes at 1:1 ratio. We continued establishing sub-cohorts among graduates of 2016, 2017, 2018 and 2019, and conducted followup surveys annually. The study included 3,620 medical graduates from the Medical College of Qinghai University (Qinghai province), Jiujiang University (Jiangxi province), Gannan Medical University (Jiangxi province), and Guangxi Medical University (Guangxi Zhuang autonomous region). Participants completed a paper questionnaire at baseline before they finished the undergraduate study. In the baseline survey, we created a WeChat group to include all participants within each school and each sub-cohort (WeChat is a widely used instant messaging app in China. The WeChat group enables to exchange communication between investigators and participants). The links of online self-reported questionnaires were sent each year with notification via WeChat groups, text messages of mobile phones, and E-mails. Till now, we have collected follow-up data in 2016, 2017, 2018, and 2020.

There are two types of medical graduates in this study, those who are required to practice in rural and remote areas after graduation (compulsory services program, $\mathrm{CSP}$ ) and common medical graduates (non-compulsory services program, NCSP). Baseline survey covered demographic characteristics, attitudes towards medical study, and preferences of career development for the two types of graduates. Response behaviors of whether participants 
provided some sensitive information were also recorded. A flow diagram that summarizes the process, baseline sample size, and follow-ups is presented in Fig. 1.

In the follow-up survey, the online questionnaire took 5-10 min to finish. Follow-up surveys mainly collected the following information: (1) current jobs: working location, professional title, job income, formally funded positions, especially for CSP graduates etc.; (2) career mobility: whether change jobs and reasons, and information about new jobs etc.; and (3) career development: promotion, residency training, and job performance etc. The content of each follow-up survey was similar. Whether breaking the contracts for CSP graduates and job income for both types of graduates could be invasive. However, these questions were asked repeatedly in each follow-up survey, the content of follow-up surveys was unlikely to have a differential impact on attrition.

Notes: the 2019 follow-up survey was not conducted for graduates of 2015-2018 due to logistic reasons.

\section{Strategies for increasing response}

To maintain the participation of medical graduates in the cohort, we mainly adopted the following strategies. First, in between scheduled follow-ups, regular newsletters were sent to the WeChat groups by project members, including national or regional policies related to CSP, newly published research concerning CSP, and greetings on important holidays. Second, we organized a writing competition each year to encourage graduates who have become GPs in rural and remote areas to share their experiences. Third, we built a liaison team composed of student leaders in the baseline survey, and asked them to send the questionnaire to graduates who did not respond.
To increase response rate, we offered ten CNY as allowances for those who completed questionnaires. If participants did not fill in the questionnaire in time, we would add them as WeChat friends, call them, or send E-mails to remind them. Besides, we would also ask liaison members to contact and remind them to fill in the questionnaire.

\section{Measurement \\ 1. Follow-up status}

Participants were categorized into two mutually exclusive groups: (1) complete follow-up refers to those who finished all follow-up surveys; (2) incomplete follow-up refers to those who did not finish at least one follow-up survey.

Participants with incomplete follow-up were further categorized into three mutually exclusive sub-groups: (1) "always-out" refers to those who did not respond to any follow-up surveys after the baseline visit, and those who could no longer be contacted through their phone, WeChat, E-mail, or other contact ways; (3) "rejoin" refers to those who finished the 2020 follow-up survey but was lost at least once in previous follow-up surveys; (4) "other" refers to those who did not respond to the 2020 follow-up survey but finished at least one previous follow-up surveys.

\section{Predictors of attrition and outcome}

For potential predictors of attrition, we tried to cover variables that were found to have impact on attrition in previous literature, and also explored some variables related to medical study. The variables were categorized into sociodemographic characteristics $[18,19]$, attitudes

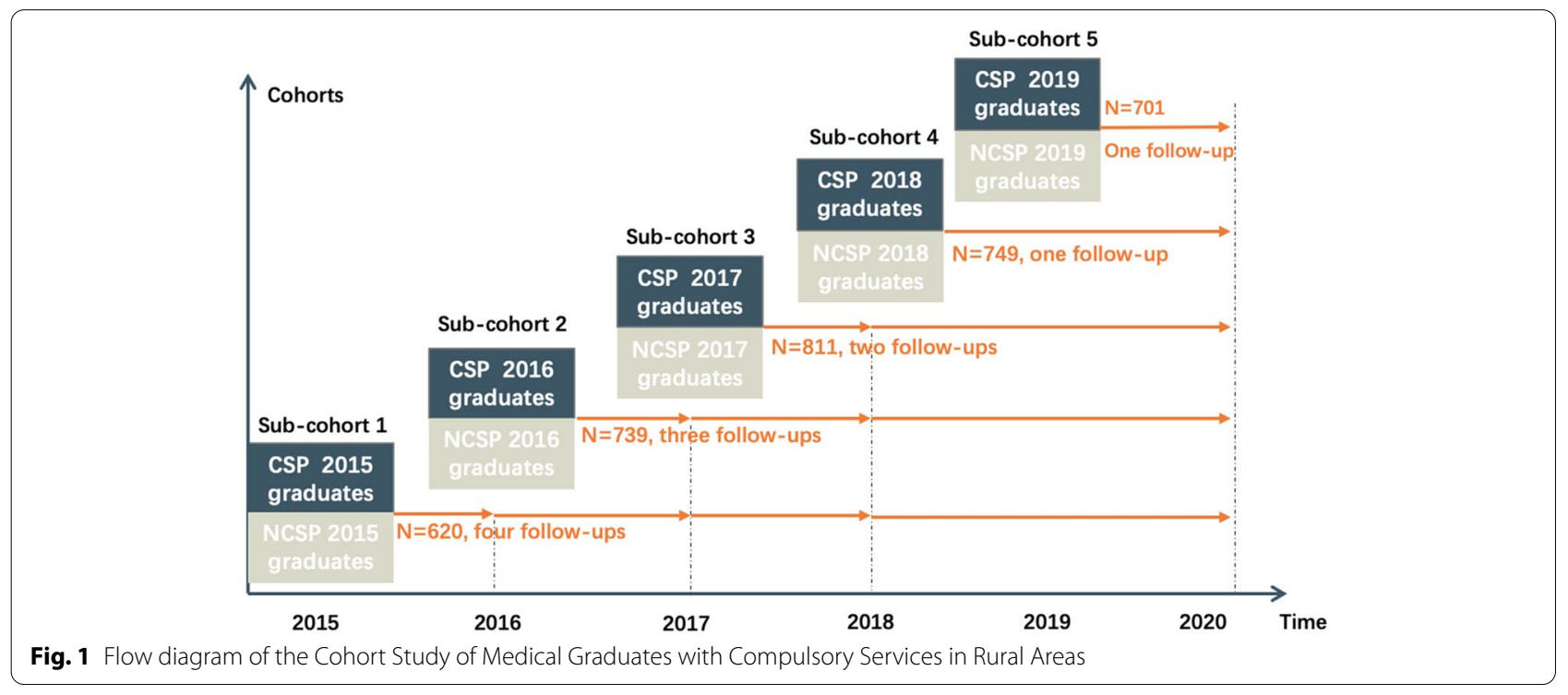


towards medical study, preferences towards career development [20], and response behaviors in the baseline survey [21]. Sociodemographic information included types of students (whether CSP or NCSP graduate), medical university (Qinghai, Guangxi, Jiujiang, Gannan), graduation year (2015-2019), gender, family background (rural or urban) [22], highest completed education level of theirs parents (low middle school and below, or high middle school and above) [18], occupation of father (farmer or non-farmer), pressure from tuition and other fee at school (having pressure or no pressure), and household members (four family members or above, three family members or below) [19]. Attitudes towards medical study comprised of whether studying medicine was the first choice, whether planning to pursue a postgraduate degree, whether willing to participate in residency training, whether satisfied with medical education received, and whether understanding compulsory services program policy for CSP graduates.

Preferences of career development included whether desired to work in public hospitals above county level after graduation, whether believing they can pass the China National Medical Licensing Examination within one year, whether income was the primary consideration when looking for jobs, and whether the contract-signing place was hometown for CSP graduates.

Response behaviors included whether provide the score of university entrance examination, whether provide contact information (we collected WeChat, QQ, E-mail, and cellphone, providing at least one way of contact was considered "provide". Providing none of the aforementioned contact was considered "not provide"). It should be noted that although we established WeChat groups in the baseline survey, students can still withdraw anytime from the group. Whether reporting household income was also included as a predictor of response behavior.

\section{Statistical analysis}

To answer question 1 , descriptive analyses were used to present the response rate of five sub-cohorts for each follow-up survey and the cumulative follow-up status ratio.

To answer question 2, firstly, the baseline characteristics between complete and incomplete follow-up of medical graduates, and among three types of attrition groups were presented. Chi-square tests were used to compare the differences between different groups of follow-up status. The P-value below 0.05 was considered statistically significant. Secondly, logistic regression was performed to investigate the factors associated with attrition of the cohort (the dependent variable was 1 for completing all follow-up surveys and 0 for incomplete) in the total sample and by types of graduates. Demographic characteristics, attitudes towards medical study, preferences towards career development, and response behaviors in baseline were included as explanatory factors in the model. In order to examine the predictors associated with rejoining, we conducted logistic regression in the incomplete sample (the dependent variable was 1 for rejoin and 0 for always-out or other). Thirdly, to rule out the effect of time, the Anderson and Gill model (AG model) was used to conduct a time-to-event analysis with recurrent events [23]. The detailed process and results was presented in the additional file.

To answer question 3, we adopted a multiple imputation method which has been widely used in dealing with missing data [24]. We performed a multiple imputation with chained equations (MICE), and all baseline variables were used to impute the interested outcome measures. For outcome measures, we chose three indicators that can reflect the career development of medical graduates, including income of the participant's current job in the 2020 wave (income was collected by the question: "your income of the current job was__CNY per month"), whether passing the China National Medical Licensing Examination (NMLE) till 2020 wave, and obtaining a professional promotion till 2020 wave. The package "ice" was used to conduct the multiple imputation process in Stata.[25]. For the three outcome measures, comparisons were made between the imputed data and the data before imputation. T-tests were used for job income, and Chisquare tests were used for the other two outcome measures. Stata 16.0 (Stata Corp LP, College Station, TX, USA) and $\mathrm{R}$ version 4.0.2 were used to perform the analysis.

\section{Results}

In total, 3620 medical graduates were included in the baseline survey from 2015 to 2019 . There were 620 participants in the 2015 sub-cohort, 739 in 2016, 811 in 2017, 749 in 2018, and 701 in 2019. The numbers were similar in CSP and NCSP medical graduates.

\section{Attrition status in follow-up surveys}

Table 1 describes the response rate of the study cohort in different follow-up surveys. In the first follow-up survey, the response rate was generally high. In the 2015 sub-cohort, the response rate was $91.9 \%$ in total, $91.5 \%$ for CSP graduates, and $92.4 \%$ for NCSP graduates. The response rate declined in each follow-up survey. After three follow-up surveys, the response rate was only $67.7 \%$. The response rate was relatively higher in CSP graduates $(78.4 \%)$ than that in NCSP graduates $(57.5 \%)$ in the fourth follow-up survey.

Figure 2 shows the cumulative follow-up status ratio by pooling all follow-ups together. Despite differences across five sub-cohorts, we found a sizable proportion of attritors who have at least one lost-to-follow-up 
Table 1 The response rate of the sub-cohorts by follow-up surveys, stratified by types of graduates N(\%)

\begin{tabular}{|c|c|c|c|c|c|}
\hline \multirow[t]{2}{*}{ Follow-up surveys } & \multicolumn{5}{|l|}{ Sub-cohorts } \\
\hline & 2015 & 2016 & 2017 & 2018 & 2019 \\
\hline \multicolumn{6}{|l|}{ - - All - - } \\
\hline Baseline N & $620(100 \%)$ & 739 (100\%) & $811(100 \%)$ & $749(100 \%)$ & $701(100 \%)$ \\
\hline First & $570(91.9 \%)$ & $577(78.1 \%)$ & $585(72.1 \%)$ & $529(70.6 \%)$ & $612(87.3 \%)$ \\
\hline Second & $424(68.4 \%)$ & $592(80.1 \%)$ & $586(72.3 \%)$ & NA & NA \\
\hline Third & $474(76.5 \%)$ & $493(66.7 \%)$ & NA & NA & NA \\
\hline Fourth & $420(67.7 \%)$ & NA & NA & NA & NA \\
\hline \multicolumn{6}{|l|}{- CSP --} \\
\hline Baseline N & $305(100 \%)$ & $437(100 \%)$ & 481 (100\%) & $437(100 \%)$ & 381 (100\%) \\
\hline First & $279(91.5 \%)$ & $373(85.4 \%)$ & $352(73.2 \%)$ & $328(75.1 \%)$ & 351 (92.1\%) \\
\hline Second & $277(90.8 \%)$ & $383(87.6 \%)$ & $383(79.6 \%)$ & NA & NA \\
\hline Third & $298(97.7 \%)$ & $330(75.5 \%)$ & NA & NA & NA \\
\hline Fourth & $239(78.4 \%)$ & NA & NA & NA & NA \\
\hline \multicolumn{6}{|l|}{$-\mathrm{NCSP}--$} \\
\hline Baseline N & $315(100 \%)$ & $302(100 \%)$ & $330(100 \%)$ & $312(100 \%)$ & $320(100 \%)$ \\
\hline First & $291(92.4 \%)$ & $204(67.6 \%)$ & $233(70.6 \%)$ & $201(64.4 \%)$ & $261(81.6 \%)$ \\
\hline Second & $181(46.7 \%)$ & $209(69.2 \%)$ & $203(61.5 \%)$ & NA & NA \\
\hline Third & $176(55.9 \%)$ & $163(54.0 \%)$ & NA & NA & NA \\
\hline Fourth & $181(57.5 \%)$ & NA & NA & NA & NA \\
\hline
\end{tabular}

Notes: NA not applicable

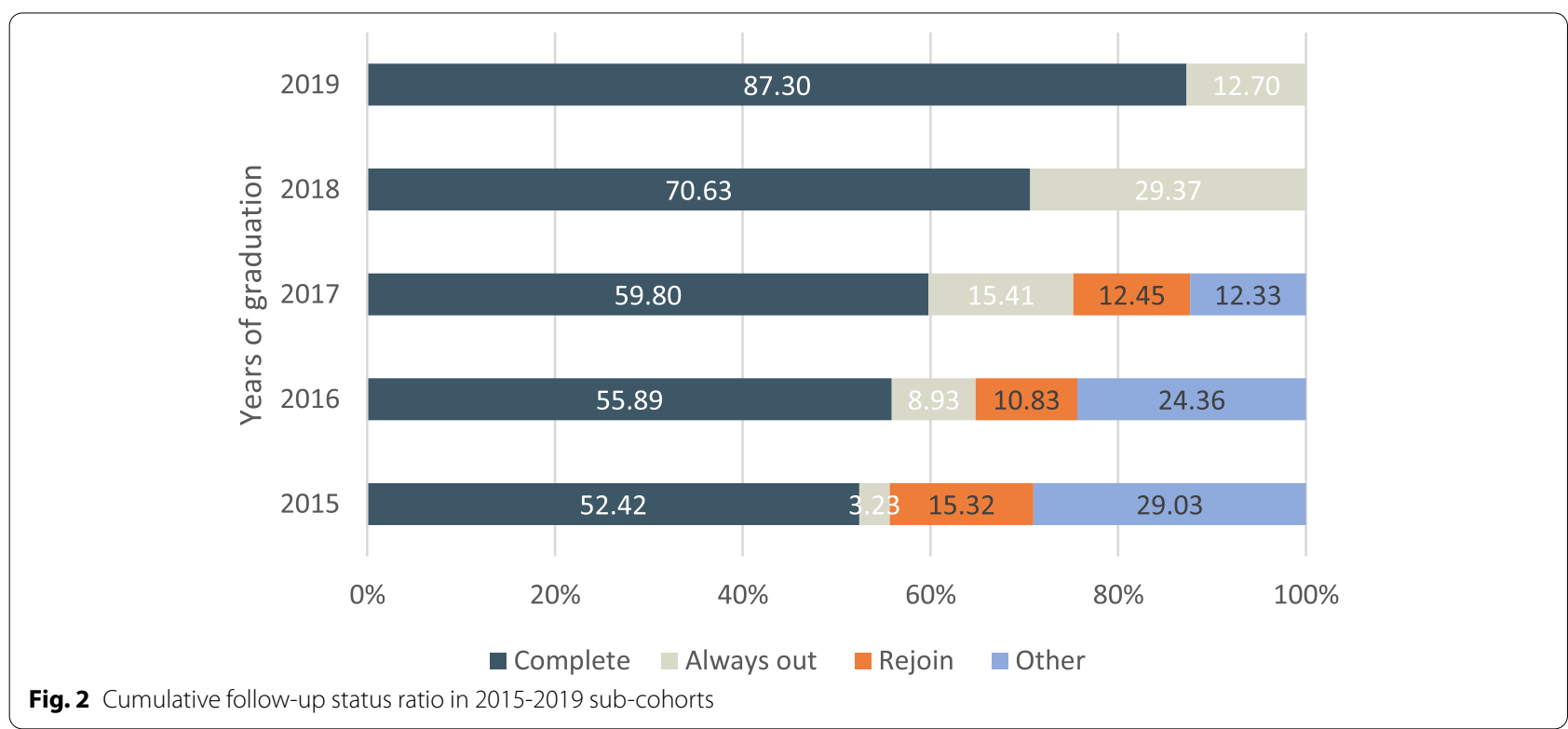

rejoined in the 2020 follow-up survey. In the 2015, 2016 and 2017 graduates, $15.3 \%, 10.8 \%$ and $12.5 \%$ rejoined in the 2020 follow-up survey, respectively. In the 2018 and 2019 graduates, because only one follow-up survey was conducted, by definition there were no 'rejoin' or 'other' categories.

\section{Determinants of attrition: baseline characteristics} by attrition status

Table 2 presents the baseline characteristics of demographic information, attitudes towards medical study, preferences of career development, and response behaviors. Participants with complete follow-up and 
Table 2 Distribution of baseline characteristics, stratified by follow-up status and groups of attrition

\begin{tabular}{|c|c|c|c|c|c|c|}
\hline \multirow[t]{2}{*}{ Characteristics } & \multicolumn{2}{|c|}{ Follow-up status } & \multirow[b]{2}{*}{$P$-value } & \multicolumn{3}{|c|}{ Attrition by groups (vs. complete) } \\
\hline & $\begin{array}{l}\text { Complete } \\
\mathrm{N} \text { (column \%) }\end{array}$ & $\begin{array}{l}\text { Incomplete } \\
\mathrm{N} \text { (column \%) }\end{array}$ & & $\begin{array}{l}\text { Always-out } \\
\mathrm{N} \text { (column \%) }\end{array}$ & $\begin{array}{l}\text { Rejoin } \\
\mathrm{N} \text { (column \%) }\end{array}$ & $\begin{array}{l}\text { Other } \\
\mathrm{N} \text { (column \%) }\end{array}$ \\
\hline Demographic information & 2364 & 1256 & & 520 & 276 & 460 \\
\hline CSP & $1495(63.2 \%)$ & $546(43.5 \%)$ & $<0.001$ & $214(41.2 \%)^{* * *}$ & $136(49.3 \%) * * *$ & $196(42.6 \%)^{* * *}$ \\
\hline \multicolumn{7}{|l|}{ Medical schools } \\
\hline Qinghai & $689(29.1 \%)$ & $455(36.2 \%)$ & $<0.001$ & $205(39.4 \%) * * *$ & $71(25.7 \%)$ & $179(38.9 \%)^{* * *}$ \\
\hline Guangxi & $719(30.4 \%)$ & $214(17.0 \%)$ & $<0.001$ & $80(15.4 \%)^{* * *}$ & $32(11.6 \%)^{* * *}$ & $102(22.2 \%)^{* * *}$ \\
\hline Jiujiang & $283(12.0 \%)$ & $197(15.7 \%)$ & 0.002 & $65(12.5 \%)$ & $73(26.4 \%)^{* * *}$ & $59(12.8 \%)$ \\
\hline Gannan & $673(28.5 \%)$ & $390(31.1 \%)$ & 0.104 & $170(32.7 \%)$ & $100(36.2 \%)^{* *}$ & $120(26.1 \%)$ \\
\hline Male & $1186(50.2 \%)$ & $643(51.5 \%)$ & 0.454 & $252(49.2 \%)$ & $152(55.1 \%)$ & $239(52.0 \%)$ \\
\hline Rural background & $1584(67.3 \%)$ & $769(61.8 \%)$ & 0.001 & $294(57.6 \%) * * *$ & $182(66.2 \%)$ & $293(63.7 \%)$ \\
\hline $\begin{array}{l}\text { Highest education level for parents were low middle } \\
\text { school and below }\end{array}$ & $1431(60.7 \%)$ & $703(56.3 \%)$ & 0.012 & $291(56.8 \%)$ & $153(55.4 \%)$ & $259(56.3 \%)$ \\
\hline Father's occupation=farmer & $1260(53.7 \%)$ & $544(43.7 \%)$ & $<0.001$ & $231(45.3 \%)^{* * *}$ & $122(44.4 \%)^{* *}$ & $191(41.6 \%)^{* * *}$ \\
\hline $\begin{array}{l}\text { Enduring pressure from tuition and other fee during } \\
\text { school }\end{array}$ & 2157 (93.1\%) & 1082 (89.4\%) & $<0.001$ & $436(87.4 \%)^{* * *}$ & $237(89.8 \%)$ & $409(91.5 \%)$ \\
\hline Four family members and above & $955(40.5 \%)$ & $417(33.5 \%)$ & $<0.001$ & $154(30.2 \%) * * *$ & $87(31.5 \%)^{* *}$ & $176(38.3 \%)$ \\
\hline \multicolumn{7}{|l|}{ Attitudes towards medical study } \\
\hline Studying medicine was first choice & $1817(77.4 \%)$ & $919(73.9 \%)$ & 0.020 & $375(73.7 \%)$ & $203(73.8 \%)$ & $341(74.1 \%)$ \\
\hline Planning to pursue postgraduate study & $1439(61.2 \%)$ & $818(66.1 \%)$ & 0.004 & $354(69.8 \%) * * *$ & $167(60.7 \%)$ & $297(65.3 \%)$ \\
\hline Willing to participate in residency training & 1957 (83.3\%) & $904(73.0 \%)$ & $<0.001$ & $374(73.2 \%) * * *$ & $201(73.1 \%)^{* * *}$ & $329(72.6 \%)^{* * *}$ \\
\hline Satisfied with medical education received & $1188(50.3 \%)$ & $540(43.4 \%)$ & $<0.001$ & $235(46.1 \%)$ & $112(40.9 \%)^{* *}$ & $193(42.0 \%)^{* *}$ \\
\hline Understanding compulsory services program & $1385(92.7 \%)$ & $499(91.4 \%)$ & 0.323 & $195(91.1 \%)$ & $122(89.7 \%)$ & $182(92.9 \%)$ \\
\hline \multicolumn{7}{|l|}{ Preferences of career development } \\
\hline $\begin{array}{l}\text { Desired to work in public hospitals above county } \\
\text { level after graduation }\end{array}$ & $1554(65.8 \%)$ & $844(67.7 \%)$ & 0.233 & $368(72.2 \%)^{* *}$ & $171(62.0 \%)$ & $305(66.3 \%)$ \\
\hline Confident of passing NMLE within one year & $1200(52.2 \%)$ & $562(46.7 \%)$ & 0.002 & $250(50.3 \%)$ & $134(50.0 \%)$ & $178(40.6 \%)^{* * *}$ \\
\hline $\begin{array}{l}\text { Income was the primary consideration when apply- } \\
\text { ing for jobs }\end{array}$ & $853(36.2 \%)$ & $400(32.2 \%)$ & 0.017 & $187(36.7 \%)$ & $82(29.8 \%)$ & $131(28.5 \%) * *$ \\
\hline Contract-signing place was hometown & $906(63.4 \%)$ & $276(53.8 \%)$ & $<0.001$ & $103(52.0 \%)$ & 75 (59.1\%) & $98(52.1 \%)^{* *}$ \\
\hline \multicolumn{7}{|l|}{ Response behaviors in baseline } \\
\hline Providing scores for university entrance exam & 1575 (67.0\%) & $775(62.7 \%)$ & 0.009 & $279(54.8 \%)^{* * *}$ & $191(70.0 \%)$ & $305(67.0 \%)$ \\
\hline Providing contact information & $2296(97.1 \%)$ & 1160 (92.4\%) & $<0.001$ & $465(89.4 \%) * * *$ & $256(92.8 \%) * * *$ & $439(95.4 \%)^{*}$ \\
\hline Reporting household income & $2250(95.2 \%)$ & 1133 (90.2\%) & $<0.001$ & $468(90.0 \%)^{* * *}$ & $252(91.3 \%)^{* *}$ & $413(89.8 \%)^{* * *}$ \\
\hline
\end{tabular}

Notes: (1) Source: Compulsory Services Program 2015-2020 cohort; (2) Chi-square test was used for categorical variables, with $p$-value reported. *** $p<0.001$, *** $p<0.05,{ }^{*} p<0.01$ (3) "Contract-signing place was hometown" and "Understanding compulsory services program" are only for CSP graduates. (4) NMLE, China National Medical Licensing Examination; NA, not applicable

those with incomplete follow-up showed significant differences. For demographic characteristics, participants with incomplete follow-up were more likely to have or to be NCSP graduates $(P<0.001)$, urban background $(P=0.001)$, non-farmer father $(P<0.001)$, having tuition or fee pressure during school $(P<0.001)$, coming from a smaller family (three family members and below, $P<0.001$ ), and having better-educated parents (high middle school or above, $P=0.012$ ). For attitudes towards medical study, participants with incomplete follow-up were more likely to choose to study medicine as their first choice when choosing college majors $(P=0.02)$, plan to pursue postgraduate study $(P=0.004)$, would like to participate in residency training $(P=0.001)$, show unsatisfied feelings towards undergraduate medical education $(P<0.001)$. As for preferences of career development, participants with incomplete follow-up tended to be less confident of oneself in passing the NMLE within one year $(P=0.002)$. CSP graduates with incomplete follow-up were more likely to sign contracts with hometowns $(P<0.001)$. About response behaviors, very few graduates did not provide contact information (since we asked them to provide several ways of contact), but the proportion of not providing contact 
was higher in the incomplete group (7.6\% in incomplete group, $2.9 \%$ in complete group, $P<0.001)$. The proportion of not providing the university entrance exam score, not reporting household income were both higher in the incomplete group (Table 2).

The baseline characteristic differences with the complete group were similar with those who rejoin and those who partially respond ("other"). However, the always-out group seemed to differ more significantly from the complete group. In the always-out group, the proportion of participants with a rural background, father's occupation being farmer, having tuition pressure, having three family members and below were significantly smaller than that in the complete group (all $P<0.001$ ) (Table 2).

\section{Factors associated with attrition}

Table 3 describes the factors associated with complete follow-up and rejoin estimating by multivariable logistic regressions. The total sample was used in regression (1), and the dependent variable was whether complete followup surveys $(1=$ incomplete, $0=$ complete). CSP graduates $(\mathrm{OR}=0.40,95 \% \mathrm{CI}[0.33-0.48])$, and having four family members and above $(\mathrm{OR}=0.84,95 \% \mathrm{CI}[0.71-1.00])$ predicted lower incomplete follow-up. Graduates who chose to study medicine as their first choice $(\mathrm{OR}=0.78$, $95 \% \mathrm{CI}[0.65-0.95])$, and those who were willing to participate in residency training $(\mathrm{OR}=0.80,95 \% \mathrm{CI}[0.66-0.98])$ were associated with a lower possibility of incomplete follow-up. Providing scores for the university entrance

Table 3 Baseline factors associated with incomplete follow-up and rejoining: multivariable logistic regression

\begin{tabular}{|c|c|c|c|c|c|c|}
\hline \multirow[t]{3}{*}{ Variables } & \multicolumn{2}{|l|}{ (1) } & \multicolumn{2}{|l|}{ (2) } & \multicolumn{2}{|l|}{ (3) } \\
\hline & \multicolumn{2}{|c|}{ All sample } & \multicolumn{2}{|c|}{$\begin{array}{l}\text { Graduates of 2015- } \\
2017\end{array}$} & \multicolumn{2}{|c|}{$\begin{array}{l}\text { Incomplete } \\
\text { samples }\end{array}$} \\
\hline & OR & $95 \% \mathrm{Cl}$ & OR & $95 \% \mathrm{Cl}$ & OR & $95 \% \mathrm{Cl}$ \\
\hline \multicolumn{7}{|l|}{ Demographic information } \\
\hline Types of students $(0=N C S P)$ & $0.40 * * *$ & $(0.33-0.48)$ & $0.37^{* * *}$ & $(0.29-0.46)$ & $1.52^{* *}$ & $(1.05-2.19)$ \\
\hline Male ( $0=$ female) & 1.07 & $(0.90-1.25)$ & 1.13 & $(0.93-1.39)$ & 0.99 & $(0.72-1.37)$ \\
\hline Rural background ( $0=$ urban $)$ & 0.97 & $(0.80-1.18)$ & 0.99 & $(0.78-1.26)$ & 1.26 & $(0.86-1.85)$ \\
\hline Highest education level of parents ( $0=$ low middle school and below) & 1.02 & $(0.85-1.22)$ & 1.00 & $(0.80-1.24)$ & 1.19 & $(0.84-1.70)$ \\
\hline Occupation of father ( $0=$ not farmer) & 0.89 & $(0.74-1.08)$ & 0.83 & $(0.66-1.04)$ & 1.33 & $(0.91-1.94)$ \\
\hline Pressure from tuition and other fee during school $(0=n o)$ & 0.76 & $(0.57-1.01)$ & $0.65^{* *}$ & $(0.45-0.95)$ & 0.97 & $(0.57-1.65)$ \\
\hline Household size ( $0=3$ and below) & $0.84^{* *}$ & $(0.71-1.00)$ & 0.90 & $(0.73-1.11)$ & 0.83 & $(0.58-1.17)$ \\
\hline \multicolumn{7}{|l|}{ Attitudes towards medical study } \\
\hline Studying medicine was first choice $(0=$ no $)$ & $0.78^{* *}$ & $(0.65-0.95)$ & 0.81 & $(0.64-1.01)$ & 1.13 & $(0.79-1.62)$ \\
\hline Planning to pursue postgraduate study $(0=$ no $)$ & 0.90 & $(0.75-1.08)$ & 0.86 & $(0.69-1.08)$ & 0.83 & $(0.58-1.19)$ \\
\hline Willing to participate in residency training $(0=$ no $)$ & $0.80^{* *}$ & $(0.66-0.98)$ & $0.76^{* *}$ & $(0.60-0.97)$ & 0.93 & $(0.64-1.36)$ \\
\hline Satisfied with medical education received $(0=$ no $)$ & 0.95 & $(0.81-1.12)$ & 0.99 & $(0.81-1.21)$ & 0.91 & $(0.65-1.26)$ \\
\hline Understanding compulsory services program ( $0=$ no) & - & - & - & - & - & - \\
\hline \multicolumn{7}{|l|}{ Preferences of career development } \\
\hline $\begin{array}{l}\text { Desired to work in public hospitals above county level after graduation } \\
(0=\text { no })\end{array}$ & 1.00 & $(0.84-1.20)$ & 1.06 & $(0.85-1.31)$ & 0.89 & $(0.63-1.25)$ \\
\hline Confidence of passing NMLE within one year $(0=$ no) & 0.99 & $(0.84-1.16)$ & 1.03 & $(0.84-1.26)$ & 1.14 & $(0.82-1.59)$ \\
\hline Income was the primary consideration when applying for jobs $(0=$ no) & 1.10 & $(0.93-1.31)$ & 1.08 & $(0.87-1.34)$ & 0.89 & $(0.63-1.26)$ \\
\hline Contract-signing place was hometown $(0=$ no $)$ & - & - & - & - & - & - \\
\hline \multicolumn{7}{|l|}{ Response behaviors in baseline } \\
\hline Providing scores for university entrance exam $(0=$ no) & $0.82^{* *}$ & $(0.69-0.97)$ & $0.76^{* *}$ & $(0.62-0.94)$ & $1.64^{* * *}$ & $(1.15-2.33)$ \\
\hline Providing contact information $(0=$ no $)$ & $0.46^{* * *}$ & $(0.32-0.66)$ & $0.36^{* * *}$ & $(0.22-0.60)$ & 0.82 & $(0.43-1.54)$ \\
\hline Providing household income $(0=$ no $)$ & $0.60^{* * *}$ & $(0.43-0.84)$ & $0.60^{* *}$ & $(0.40-0.89)$ & 0.87 & $(0.49-1.54)$ \\
\hline Constant & $17.33^{* * *}$ & $(8.89-33.81)$ & $27.90^{* * *}$ & $(12.00-64.87)$ & $0.22^{* * *}$ & $(0.07-0.65)$ \\
\hline Number of observations & 3,310 & & 1,930 & & 840 & \\
\hline
\end{tabular}

Notes: (1) Source: Compulsory Services Program 2015-2020 wave; (2) Robust 95\% Cl in parentheses, ${ }^{* *} p<0.01,{ }^{* *} p<0.05$ (3) Logistic regression was conducted, with odds ratio reported. The schools and years of graduation for each sub-cohort were controlled for in all regressions to control for cohort effects. (4) The dependent variable was dichotomous, $1=$ incomplete and $0=$ complete; in regression 3 , the incomplete samples included always-out, rejoin, and other, and the dependent variable was 1 for rejoin and $0=$ always-out or other. (5) NMLE China National Medical Licensing Examination; OR odds ratio; $C l$ confidence interval; NA not applicable; NCSP non-compulsory services program 
exam $(\mathrm{OR}=0.82,95 \% \mathrm{CI}[0.69-0.97])$, providing contact information $(\mathrm{OR}=0.46,95 \% \mathrm{CI}[0.32-0.66])$ and providing household income $(\mathrm{OR}=0.60,95 \% \mathrm{CI}[0.43-0.84])$ all significantly reflected the lower possibility of incomplete follow-up (Table 3).

In regression (2), we restricted the sample to graduates of 2015-2017, excluding graduates of 2018 \& 2019 who had only one follow-up survey. The results were similar to that in regression (1). However, the tuition/fee pressure in school was associated with a lower possibility of incomplete follow-up surveys $(\mathrm{OR}=0.65,95 \% \mathrm{CI}[0.45$ 0.95]). Wiliness of studying medicine was not significant anymore. Overall, these two factors might have an inconsistent effect on follow-up status (Table 3). We further conducted separate estimates for CSP and NCSP graduates, the results were reported in the additional file.

\section{Factors associated with rejoining in the survey}

In order to explore the factors associated with rejoining, we conducted Logistic regression among the attrition participants (Table 3). CSP graduates were 1.52 times more likely to come back to the survey than NCSP graduates $(\mathrm{P}<0.05)$. Medical graduates who provided university entrance exam scores were 1.64 times more likely to rejoin in the 2020 follow-up survey compared with those who did not provide $(\mathrm{P}<0.05)$.

\section{Estimating the effect of attrition on three outcome measures}

In Table 4, we compared the data before imputation and imputed data for three key outcome measures related to career development (Table 4). Overall, the results showed that the three imputed outcome measures did not have significant difference with the outcome measures before imputation, which indicated that attrition might have no impact on outcomes. For job income, before imputation, the mean job income was 4022.8 CNY for CSP graduates, and 4065.3 CNY after imputation. The imputed job income did not have significant differences compared with that before imputation $(\mathrm{P}=0.104)$. for whether passing the NMLE, $93.8 \%$ and $93.3 \%$ of CSP graduates passed the NMLE before and after imputation, respectively, and the imputed data did not differ significantly with that before imputation $(\mathrm{P}=0.148)$. for whether obtaining a professional title, there were $62.0 \%$ of CSP graduates obtained a title in the dataset; after imputation, $61.7 \%$ of CSP graduates obtained a title, and the difference was not significant, again. The results were similar for NCSP graduates.

\section{Discussion}

This paper examined the determinants of attrition in a prospective cohort comprised of young medical graduates, explored factors associated with attrition and rejoining, and assessed the impact of attrition on outcome measures of career development for young medical graduates. Several key findings were highlighted. First, the attrition increased with more follow-up surveys and $67.7 \%$ of the participants remained in the cohort after four follow-up surveys. The cumulative follow-up ratio was above $50 \%$ in all five sub-cohorts. Second, graduates who reported lower preference towards residency training and who did not provide sensitive information were associated with higher attrition, while CSP graduates and those who provided university entrance scores were more likely to rejoin the cohort.

Table 4 Results of three outcome variables of career development before and after multiple imputation

\begin{tabular}{|c|c|c|c|c|c|c|}
\hline \multirow[t]{2}{*}{ Variables } & \multicolumn{3}{|l|}{$\mathrm{CSP}(\mathrm{N}=1233)$} & \multicolumn{3}{|l|}{$\operatorname{NCSP}(\mathrm{N}=947)$} \\
\hline & Before imputation & After imputation & $P$-value ${ }^{\#}$ & Before imputation & After imputation & $P$-value \\
\hline Income of current job & $4022.8(3868.9)$ & $4065.3(3555.9)$ & 0.104 & $6456.1(5267.2)$ & $6420.9(4269.9)$ & 0.714 \\
\hline Missing & 301 & 36 & & 547 & 61 & \\
\hline \multicolumn{7}{|c|}{ Whether passing the NMLE } \\
\hline No & $59(6.2 \%)$ & $80(6.7 \%)$ & 0.148 & $51(9.3 \%)$ & $91(10.1 \%)$ & 0.329 \\
\hline Yes & $893(93.8 \%)$ & $1110(93.3 \%)$ & & $496(90.7 \%)$ & 809 (89.9\%) & \\
\hline Missing & 271 & 33 & & 400 & 47 & \\
\hline \multicolumn{7}{|c|}{ Whether obtained a professional title } \\
\hline No & $362(38.0 \%)$ & $456(38.3 \%)$ & 0.676 & $322(58.9 \%)$ & $527(58.6 \%)$ & 0.814 \\
\hline Yes & $590(62.0 \%)$ & $734(61.7 \%)$ & & $225(41.1 \%)$ & $373(41.4 \%)$ & \\
\hline Missing & 271 & 33 & & 400 & 47 & \\
\hline
\end{tabular}

Notes: (1) Source: Compulsory Services Program 2015-2017 wave; (2) Mean and standard deviation are reported for income; N and column \% are reported for categorical variables; (3) The P-value was obtained by comparing data before imputation and the imputed data, not with the total data after imputation. T-test was used to examine the differences of "income of current job", and Chi-square test was used for "whether passing the NMLE" and "whether obtained a professional title"; (4) NMLE China National Medical Licensing Examination; CSP compulsory services program, NCSP non-compulsory services program 
Third, despite the systematic differences detected among different follow-up status, no statistically significant impacts were found on the outcome measures.

In countries that established similar compulsory services policies or programs aiming to bridge the health workforce gap, we did not find studies that examine attrition in similar cohorts of medical graduates [26]. Japan established a CSP in 1972 in Jichi Medical University and trained rural doctors under contracts. However, the study they conducted was a retrospective cohort study rather than a prospective one $[27,28]$. Graduates with certain characteristics may be reluctant to join in the study, which would cause selection bias, decreasing the power of the study. Among other cohort studies that focused on health professionals, the MABEL longitudinal survey in Australia was a famous large nationwide prospective cohort study, aiming to investigate factors influencing participation and supply of health workforce, specialty choice and mobility of health workforce. They included new doctors in subsequent follow-up to replace any attrition and maintain the cross-sectional representativeness of each follow-up [8, 29], so their patterns of attrition would be systematically different from ours.

CSP had a significant higher response rate compared with NCSP graduates. There are several potential explanations. CSP students need to sign contracts with medical universities and local governments and promise to practice in designated rural areas for six years. Through fulfilling the contracts, CSP graduates' spirits of contract and sense of responsibility are intensified virtually. They are more likely to remain in the cohort and fill in the follow-up questionnaires. After several follow-up surveys, participation might become a habit so that participants no longer consider whether to respond or not, but "participate because they have done so all along" [30]. For NCSP graduates, they do not possess a contract or even any obligations of becoming doctors. NCSP graduates are more likely to leave the medical industry and pursue other careers than CSP graduates. Choosing careers elsewhere indicates that medicine is not their interests, and surveys related to medical career development become less attractive to them.

Unwillingness to participate in residency training was associated with a higher possibility of attrition. According to the national policy in China starting in 2015, all medical graduates need to participate in residency training after graduation [14], which generally lasts for three years [31]. For CSP graduates, the three years of training are included in the six-year service period stipulated in the contract. Not willing to participate in residency training suggests that the CSP graduates may be more likely to break the contracts and the NCSP graduates are more likely to leave the medical industry, so they would be reluctant to remain in the cohort established in their medical universities.

We found the response behaviors were consistently associated with attrition. Graduates who did not provide scores for the university entrance exam, contact information, or household income in the baseline survey were more likely to attrite. This finding was consistent with previous research [22,32]. The completeness of information provided can reflect participants' willingness towards the survey and persistently participating in the survey. Not providing contact information could be viewed as an indirect way of withdrawing from the cohort study or a 'polite' refusal. Students who did not provide key information at baseline should be targeted early since they are ready to leave cohorts from the beginning.

More than $10 \%$ of rejoining participants indicates that those rejoiners should be examined for scrutiny [33]. CSP and reporting score for university entrance exam predicted higher possibility of rejoining. Cheng and Trivedi (2015) estimated the attrition bias in the MABEL study [3]. They also found a significant faction of attriting physicians (approximately 23 to $32 \%$ of the drop-outs) rejoined the study. They attributed this phenomenon to changes in work (or residential) address, causing them unreachable. Since our follow-up surveys are conducted online, we think there are other two factors contributing to rejoining. First, the work status may help to explain the rejoining. Graduates need time to fit in the new working environment in their new occupations. This period of adaption poses more challenges on them, resulting in no time or interest to handle a non-mandated survey. After settling down in the new environment, they would have more control over their time so they would fill in the follow-up questionnaires. Besides, the work attitudes and efforts of investigators may also explain the rejoining to some extent.

Importantly, the systematic differences across attrition groups seemed not to have significant impact on key outcome measures of career development. Our finding adds to a growing body of literature suggesting that selective attrition does not necessarily twist the estimates of outcomes [34-36]. It might be optimistic to interpret future results without special caution on attrition bias based on current response rate.

A key strength of this study was that we examined the attrition and rejoin in a prospective cohort comprised of young medical graduates. Younger population and medical professionals are less likely to stay in the cohort as aforementioned, but we managed to assess attrition in a cohort composed of young medical graduates. To our knowledge, this is the first study examining attrition in such a cohort. A limitation of this study is the short follow-up period. The first group of graduates were only 
followed four times, and graduates of 2018 and 2019 were only followed once due to COVID-19 pandemic. It particularity limited the sample size when assessing the impact of attrition on outcome measures of career development. The career development of those graduates remains to be observed in the future. Another limitation is unmeasured confounders that would potentially affect follow-up status and outcome measures, for example, the working mode, or the professionalism of the graduates. Future studies should take those unmeasured factors into consideration when interpreting results.

\section{Conclusions}

In a prospective cohort comprised of young health professionals, those who were unwilling to participate in residency training and those who did not provide sensitive information were associated with higher attrition. These graduates should be targeted early. The researchers should provide more background information of the study to help them understand the meaning of their participation. For graduates who have the potential of rejoining, more efforts should be invested to maintain their participation. Despite the systematic differences detected among different follow-up status, they do not have significant impacts on the outcome measures of career development.

\section{Supplementary Information}

The online version contains supplementary material available at https://doi. org/10.1186/s12874-021-01498-1.

Additional file 1.

\section{Acknowledgements}

The authors want to thank Qinghai University, Jiujiang University, Gannan Medical University, and Guangxi Medical University for their support in the establishment of the cohorts.

\section{Authors' contributions}

$\mathrm{ML}$ drafted the manuscript, conducted the data analysis and interpretation. ZW designed the study, conducted the data analysis and managed the data. BZ, TW, DH collected and managed the data. XL designed the study, and made critical interpretations and revisions on intellectual contents of the article. All authors read and approved the final manuscript.

\section{Funding}

The Cohort Study of Medical Graduates with Compulsory Services in Rural Areas Studies was funded by China Medical Board (CMB). The funder had no role in study design, data collection, data analysis, data interpretation, or writing of the report.

\section{Availability of data and materials}

The datasets generated and/or analyzed during the current study are not publicly available due to limitations of ethical approval involving the personal data and anonymity but are available from the corresponding author on reasonable request.

\section{Declarations}

\section{Ethics approval and consent to participate}

The study has been approved by the Institutional Review Board of Peking University Health Science Center (PU IRB) (IRB00001052-15027) and was performed in accordance with the Declaration of Helsinki. Written informed consent was obtained from all participants prior to questionnaire administration.

\section{Consent for publication}

Not applicable.

\section{Competing interests}

The authors declare that they have no competing interests.

\section{Author details}

${ }^{1}$ Department of Health Policy and Management, School of Public Health, Peking University, Beijing, China. ${ }^{2}$ China Center for Health Development Studies, Peking University, Beijing, China.

Received: 15 June 2021 Accepted: 23 December 2021

Published online: 14 January 2022

\section{References}

1. Dowell J, Cleland J, Fitzpatrick S, et al. The UK medical education database (UKMED) what is it? Why and how might you use it? BMC medical education. 2018;18(1):6-6. https://doi.org/10.1186/s12909-017-1115-9.

2. Cook DA, Andriole DA, Durning SJ, Roberts NK, Triola MM. Longitudinal research databases in medical education: facilitating the study of educational outcomes over time and across institutions. Acad Med Aug. 2010;85(8):1340-6. https://doi.org/10.1097/ACM.0b013e3181e5c050.

3. Cheng TC, Trivedi PK. Attrition bias in panel data: A sheep in wolf's clothing? A case study based on the MABEL survey. Health economics. 2015;24(9):1101-17.

4. Watson D. Sample attrition between waves 1 and 5 in the European Community Household Panel. European Sociological Review Sep. 2003;19(4):361-78. https://doi.org/10.1093/esr/19.4.361.

5. Asch DA, Jedrziewski MK, Christakis NA. Response rates to mail surveys published in medical journals. Journal of clinical epidemiology. 1997;50(10):1129-36.

6. Cho YI, Johnson TP, Vangeest JB. Enhancing surveys of health care professionals: a meta-analysis of techniques to improve response. Eval Health Prof Sep. 2013;36(3):382-407. https://doi.org/10.1177/0163278713 496425.

7. Yan W, Cheng TC, Scott A, et al. Medicine in Australia: Balancing Employment and Life (MABEL). Australian Economic Review. 2011;44(1):102-12.

8. Joyce CM, Scott A, Jeon SH, et al. The "medicine in Australia: balancing employment and life (MABEL)" longitudinal survey--protocol and baseline data for a prospective cohort study of Australian doctors' workforce participation. BMC Health Serv Res Feb. 2010;25:50. https://doi.org/10.1186/ 1472-6963-10-50.

9. Goldberg M, Chastang JF, Zins M, Niedhammer I, Leclerc A. Health problems were the strongest predictors of attrition during follow-up of the GAZEL cohort. J Clin Epidemiol Nov. 2006;59(11):1213-21. https://doi. org/10.1016/j.jclinepi.2006.02.020

10. Tate $A R$, Jones $M$, Hull $L$, et al. How many mailouts? Could attempts to increase the response rate in the Iraq war cohort study be counterproductive? BMC Med Res Methodol Nov. 2007;28:51. https://doi.org/10. 1186/1471-2288-7-51.

11. Cunradi CB, Moore R, Killoran M, Ames G. Survey nonresponse bias among young adults: the role of alcohol, tobacco, and drugs. Subst Use Misuse. 2005;40(2):171-85. https://doi.org/10.1081/ja-200048447.

12. Young AF, Powers JR, Bell SL. Attrition in longitudinal studies: who do you lose? Aust N Z J Public Health Aug. 2006;30(4):353-61. https://doi.org/10. 1111/j.1467-842x.2006.tb00849.x.

13. Powers J, Tavener M, Graves A, Loxton D. Loss to follow-up was used to estimate bias in a longitudinal study: a new approach. J Clin Epidemiol Aug. 2015;68(8):870-6. https://doi.org/10.1016/j.jclinepi.2015.01.010. 
14. Notice on Issuing the Implementation Opinions on Medical Students of Compulsory Services Programs for Rural Areas (2010).

15. Wang Z, Hu D, Z B, et al. Analysis on the targeted admission medical graduates and their work preference in rural areas: A three-year survey conducted in four medical schools (in Chinese). Chinese Journal of Health Policy. 2020;13(11):57-62.

16. Zhang C, Chen C, Zhang Z, et al. Study on the current employment situation of targeted admission medical graduates in rural areas (in Chinese). Chinese Jounal of Health Policy. 2017;10(5):27-33.

17. Zhang Z, Zhang $C$, Huang M, et al. Two-year follow-up analysis of targeted admission medical graduates in rural areas (in Chinese). Chinese Journal of Health Policy. 2018;11(9):34-9.

18. Groves RM, Couper MP. Nonresponse in household interview surveys. John Wiley \& Sons; 2012.

19. Uhrig S. The nature and causes of attrition in the British Household Panel Study. 2008.

20. Loosveldt G, Carton A. An empirical test of a limited model for panel refusals. International Journal of Public Opinion Research. 2001;13(2):173-85.

21. Branden L. The Effect of Interview Length on Attrition in the National Longitudinal Survey of Youth. National Longitudinal Surveys Discussion Paper. 1995:

22. Sun Y, Zou Y, Ding H, Yan J, Gu J, Qiu Z. Effects of Respondent Household and Its Head's SES on Panel Refusal:A case study of CFPS (in Chinese). Sociological Studies. 2011;000(002):167-81.

23. Amorim LD, Cai J. Modelling recurrent events: a tutorial for analysis in epidemiology. International journal of epidemiology. 2015;44(1):324-33.

24. Sterne JA, White IR, Carlin JB, et al. Multiple imputation for missing data in epidemiological and clinical research: potential and pitfalls. Bmj. 2009;338

25. Royston P, White IR. Multiple Imputation by Chained Equations (MICE): Implementation in Stata. 2011. 2011-12-12 2011;45(4):20. doi:https://doi. org/10.18637/jss.v045.i04

26. Frehywot S, Mullan F, Payne PW, Ross H. Compulsory service programmes for recruiting health workers in remote and rural areas: do they work? Bull World Health Organ May. 2010;88(5):364-70. https://doi.org/10.2471/blt. 09.071605 .

27. Matsumoto M, Inoue K, Kajii E. A contract-based training system for rural physicians: follow-up of Jichi Medical University graduates (1978-2006). J Rural Health Fall. 2008;24(4):360-8. https://doi.org/10.1111/j.1748-0361. 2008.00182.x

28. Matsumoto M, Inoue K, Kajii E. Long-term effect of the home prefecture recruiting scheme of Jichi Medical University, Japan. Rural Remote Health Jul-Sep. 2008;8(3):930.

29. Yan WD, Cheng TC, Scott A, et al. Medicine in Australia: Balancing Employment and Life (MABEL). Australian Economic Review Mar. 2011;44(1):10212. https://doi.org/10.1111/j.1467-8462.2010.00627.x.

30. Lugtig P. Panel attrition: separating stayers, fast attriters, gradual attriters, and lurkers. Sociological Methods \& Research. 2014;43(4):699-723.

31. Zhu J, Li W, Chen L. Doctors in China: improving quality through modernisation of residency education. Lancet Oct. 2016;15(10054):1922-9. https://doi.org/10.1016/s0140-6736(16)00582-1.

32. Burton J, Laurie H, Lynn P. The long-term effectiveness of refusal conversion procedures on longitudinal surveys. Journal of the Royal Statistical Society: Series A (Statistics in Society). 2006;169(3):459-78.

33. Cheng TC, Trivedi PK. Attrition Bias in Panel Data: A Sheep in Wolf's Clothing? A Case Study Based on the Mabel Survey. Health Econ Sep. 2015;24(9):1101-17. https://doi.org/10.1002/hec.3206.

34. Cameron CM, Osborne JM, Spinks AB, Davey TM, Sipe N, McClure RJ. Impact of participant attrition on child injury outcome estimates: a longitudinal birth cohort study in Australia. BMJ Open. Jun 30 2017;7(6):e015584. doi:https://doi.org/10.1136/bmjopen-2016-015584

35. Wolke D, Waylen A, Samara M, et al. Selective drop-out in longitudinal studies and non-biased prediction of behaviour disorders. Br J Psychiatry Sep. 2009;195(3):249-56. https://doi.org/10.1192/bjp.bp.108.053751.

36. Osler M, Kriegbaum M, Christensen U, Lund R, Nybo Andersen AM. Loss to follow up did not bias associations between early life factors and adult depression. J Clin Epidemiol Sep. 2008;61(9):958-63. https://doi.org/10. 1016/j.jclinepi.2007.11.005.

\section{Publisher's Note}

Springer Nature remains neutral with regard to jurisdictional claims in published maps and institutional affiliations.
Ready to submit your research? Choose BMC and benefit from:

- fast, convenient online submission

- thorough peer review by experienced researchers in your field

- rapid publication on acceptance

- support for research data, including large and complex data types

- gold Open Access which fosters wider collaboration and increased citations

- maximum visibility for your research: over $100 \mathrm{M}$ website views per year

At BMC, research is always in progress.

Learn more biomedcentral.com/submissions 